\title{
Comparative study on welding characteristics of laser-additional current hybrid welded T-joint of aluminium and titanium alloy
}

\author{
Xinge Zhang ${ }^{1,2, a}$, Liqun $\mathrm{Li}^{2}$, Yanbin Chen ${ }^{2}$, Xiaocui Zhu ${ }^{1}$, Yansheng $\mathrm{Li}^{2}$, Xinjian Guo ${ }^{2}$ \\ 1 School of Mechanical Science and Engineering, Jilin University, China \\ 2 State Key Laboratory of Advanced Welding and Joining, Harbin Institute of Technology, China
}

\begin{abstract}
In order to improve the properties of laser overlap welded T-joint, laser-additional current hybrid welding process is put forward. In this paper, the welding characteristics of laser-additional current hybrid welded aluminum and titanium alloy T-joint were conducted and compared. The weld width at faying surface increase, which results in tensile shear load increasing compared with those of laser welding for both aluminum and titanium alloy, but the effect of current on aluminum alloy is more obvious. The porosity defect within the laser-additional current hybrid welded joint sharply reduces compared with that within laser welding. The tensile shear load of aluminum alloy and titanium alloy hybrid welded joints respectively increase $21 \%$ and $15 \%$. The effects of additional current on welding characteristics of aluminum alloy and titanium alloy are compared and analyzed.
\end{abstract}

\section{Introduction}

The demand for lighter, lower costs and safer structures has motivated the need to study new materials and new structural configurations in automotive, ship and aerospace industries, and the skin-stringer structures offer an option that can satisfy these requirements [1-3]. The typical skin-stringer structures consist of two skin plates separated and supported by some flat stringers. The skin plates and flat stringers can be joined by mean of adhesive bonding or welding [4-6]. Owning to the high strength and resistant to high-temperature, the welding is better choice to produce the skin-stringer structure compared with adhesive bonding. The skin-stringer closed structures must been produced by stake welding which has to be done from the outside of the structure. High energy beam stake-welding such as laser welding and electron beam welding has the potential to produce skin-stringer closed structures due to the advantages of high energy density, high depth-width ratio and low welding deformation. Since the skin-stringer structures always have large size, it is difficult to be produced using the electron beam welding [7]. Laser welding is one of the most suitable processes for stake-welded skin-stringer closed structures, as shown in Reference [6].

However, when the skin-stringer structures are carried out using laser overlap welding, the weld width on skinstringer faying surfaces is not sufficient to load large tensile shear load as the narrow laser weld. Although it is possible to increase weld width through increasing the heat input, it will cause more residual stress. Moreover, in order to obtain good bonding at the faying surface, the accurate assembly is required during laser overlap welding of skin-stringer structure. In present paper, for the purpose of increasing weld width at faying surface, the additional current supply attachments are designed and used to assist laser overlap welded skin-stringer structure. Furthermore, the skin plate and stringer will closely touch each other with the additional attachments during laser overlap welding, which is beneficial to reduce weld defects at faying surface.

In this study, the comparative investigation of laseradditional current hybrid welded process were performed on 5A06 aluminum alloy and Ti6Al4V titanium alloy Tjoint which are widely applied on aerospace, ship, automotive and industries. The welding characteristics including appearance of weld bead, porosity defect and mechanical properties of laser-additional current hybrid welded $\mathrm{T}$-joint for aluminum and titanium alloy were investigated.

\section{Experimental procedures}

\subsection{Experimental material}

The base metal employed in this study is Ti6A14V titanium alloy and 5A06 aluminum alloy plate. The chemical composition (wt\%) of Ti6A14V titanium alloy is: 5.5-6.8 A1; 3.5-4.5 V; 0.3 Fe; $0.15 \mathrm{Si}$; $0.2 \mathrm{O}$; balance Ti. The Ti6Al4V alloy specimens were primarily wiped with acetone to remove grease and dirt, then pickled using a solution of $\mathrm{HNO}_{3}, \mathrm{HF}$ and distilled water to remove oxides; at last, the specimens were cleaned with distilled water and dried in a desiccator before welding. The chemical composition(wt.\%) of 5A06 aluminum

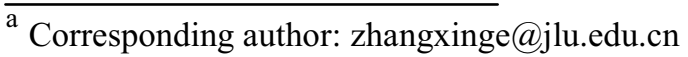


alloy is: $5.8-6.8 \mathrm{Mg}$; 0.5-0.8 $\mathrm{Mn}$; $0.4 \mathrm{Si}$; $0.1 \mathrm{Cu}$; 0.02 Ti; $0.4 \mathrm{Fe}$; $0.2 \mathrm{Zn}$; balance Al. The 5A06 alloy specimens were brushed with a stainless steel brush to remove impurities and oxides from their surfaces followed by degreasing by using an acetone solution.

\subsection{Experimental method}

Additional current applied devices were designed and equipped. The T-joints were carried out by laseradditional current hybrid overlap welding, as shown in Figure 1. During laser-additional current hybrid overlap welding, two wheel electrodes were placed on the skin surface, which rotated around fixed axes. The laser irradiated on the skin top surface located in the middle of the two rollers and the T-joint specimens moved with traveling device. Highly pure argon as a shielding gas at a flow rate of $25 \mathrm{l} / \mathrm{min}$ was supplied to suppress laser induce plasma and protect high-temperature weld pool by means of a side copper nozzle with an inner diameter of $8 \mathrm{~mm}$ at $45^{\circ}$ inclination.

After welding, the welded specimens were inspected using X-ray to observe the porosity. The photographs of weld appearance were taken by using an optical microscope (Eclipse E200, Nikon). The specimens for tensile shear test were designed as shown in Figure 2. The tensile shear test was performed by means of Instron5500R material tensile machine.

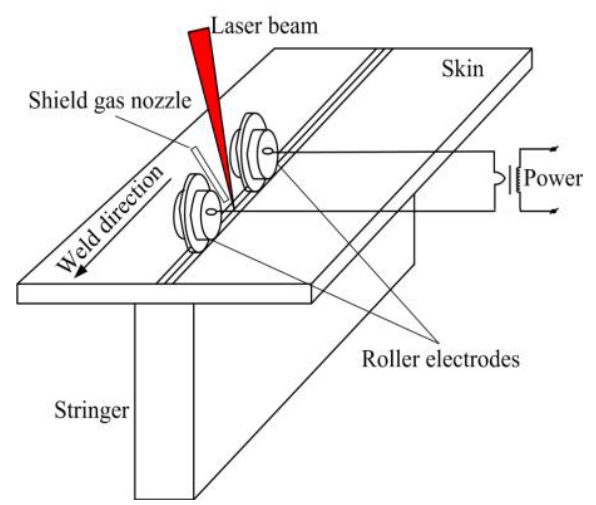

Figure 1. Schematic diagram of hybrid welding.

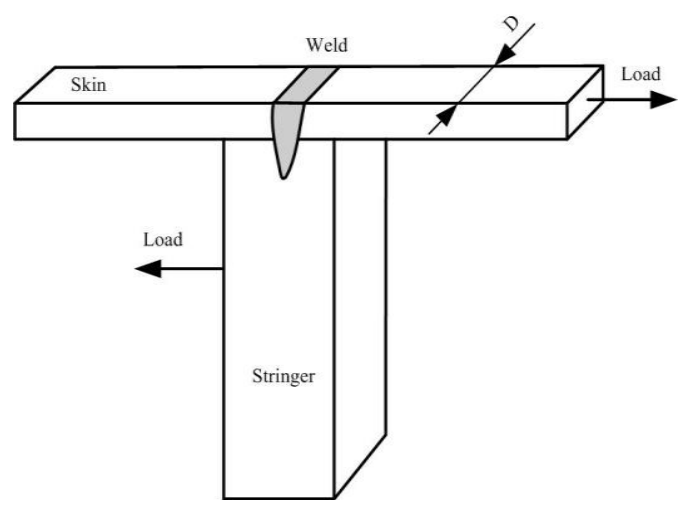

Figure 2. Dimension of tensile specimen.

\section{Results}

\subsection{Cross section of weld}

The graphs in Figure 3 and Figure 4 show the cross section characteristics of 5A06 aluminum alloy and Ti6Al4V titanium alloy welded joints respectively. It can be seen that cross section of laser welds are typical "V" profile and the weld width at faying surface decrease sharply from skin to stringer, as shown in Figure 3(a) and Figure 4(a). When the T-joint was carried out by laser-additional current hybrid welding process, the skin and stringer were contact with each other tightly and the weld width at faying surface increased evidently compared with that of laser welding, as shown in Figure 3 and Figure 4. For the 5A06 aluminum alloy hybrid welded T-joint, the weld width at faying surface is either greater also less that at top surface with the different additional current value, and the weld penetration increase obviously with moderate additional current value. However, for the Ti6Al4V titanium alloy hybrid welded T-joint, the weld width at faying surface is less that at top surface and the weld penetration is deeper with larger additional current value.

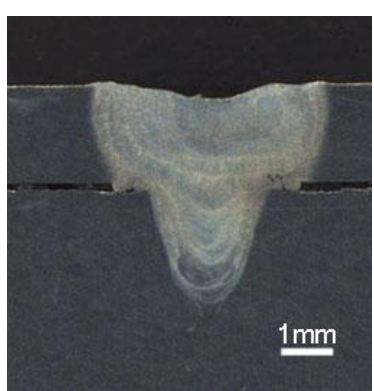

(a) Laser welding $(I=0)$

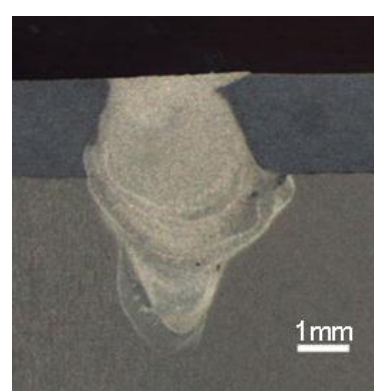

(b) Current $I=3.4 \mathrm{kA}$

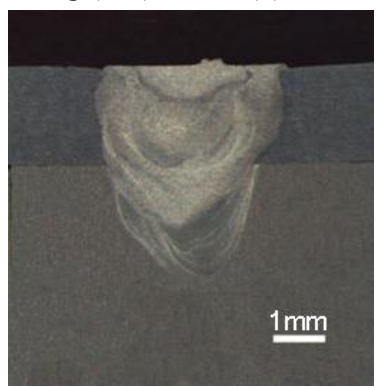

(c) Current $I=4.5 \mathrm{kA}$

Figure 3. Typical cross section of 5A06 alloy welded joints.

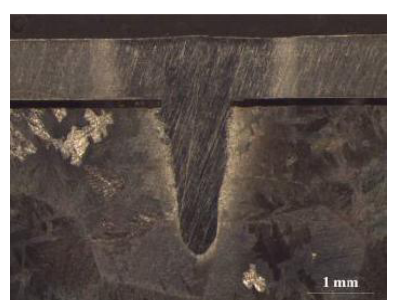

(a) Laser welding $(I=0)$

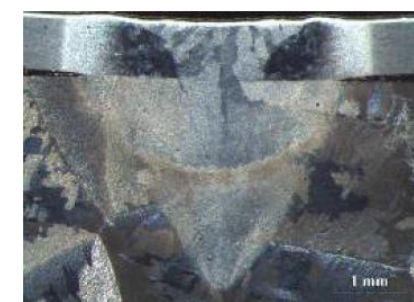

(b) Current $I=2.0 \mathrm{kA}$

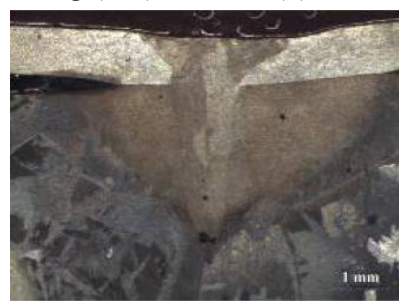

(c) Current $I=3.0 \mathrm{kA}$

Figure 4. Typical cross section of Ti6Al4V alloy welded joints. 
During laser-additional current hybrid welded 5A06 aluminum alloy $\mathrm{T}$-joint, if the additional current was higher than $5.0 \mathrm{kA}$, the welding process was very unstable with many spatters, producing poor weld appearance. When laser-additional current hybrid welded Ti6Al4V titanium alloy T-joint, the additional current wasn't higher than $3.0 \mathrm{kA}$ taking into account the easily oxidized of titanium alloy. Figure 5 and Figure 6 respectively shows the effect of current on the weld width at faying surface with the other parameters in the same conditions. From Figure 5 and Figure 6, it is clear that with an increase of current, the weld width at faying surface all increase for 5A06 aluminum alloy and Ti6Al4V titanium alloy welded $\mathrm{T}$-joint and the effect of current on 5A06 alloy welded $\mathrm{T}$-joint is more obvious compared with that of Ti6Al4V alloy.

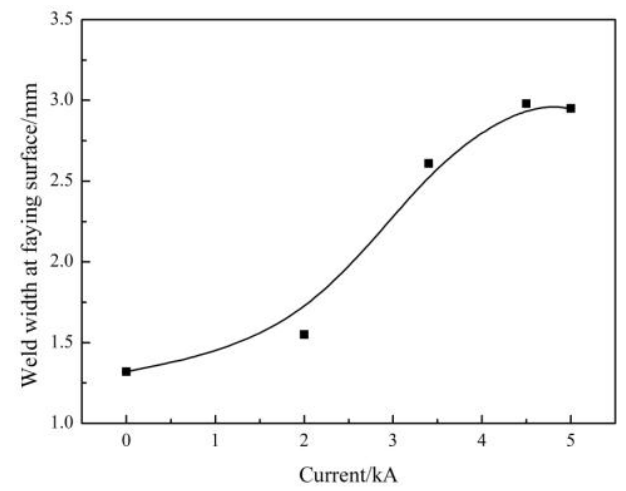

Figure 5. Effect of current on weld width at faying surface of $5 \mathrm{~A} 06$ alloy welded joints $(\mathrm{P}=1600 \mathrm{~W}, v=0.48 \mathrm{~m} / \mathrm{min})$.

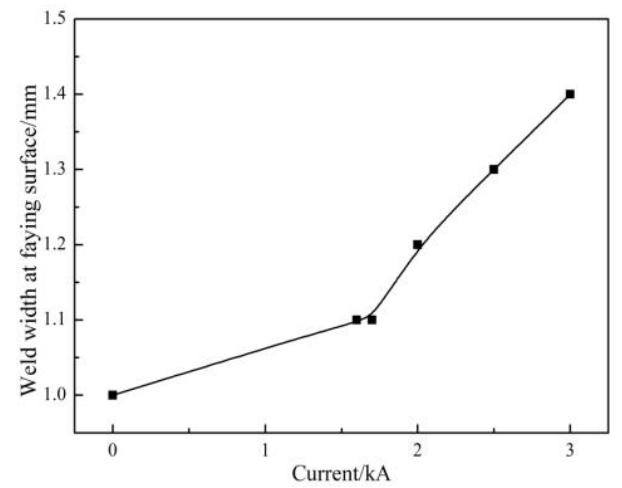

Figure 6. Effect of current on weld width at faying surface of Ti6Al4V alloy welded joints $(\mathrm{P}=1700 \mathrm{~W}, v=1.00 \mathrm{~m} / \mathrm{min})$.

\subsection{Porosity defect in welded joints}

Porosity defects are a major problem during the laser welding of aluminum alloy and titanium alloy, and such defects should result in bad sealing performance, lower fatigue resistance, and in a loss of fracture toughness. Porosity in welded joints was observed by using X-ray radiography and the white points are X-ray radiography image of porosity, as shown in Figure 7 and Figure 8. There are certain amount porosity exists in laser weld no matter 5A06 alloy or Ti6Al4V alloy welded T-joint, but the size of porosity in 5A06 alloy laser weld is larger compared with Ti6Al4V alloy laser weld. As shown in Figure $7(\mathrm{~b})$ and Figure $8(\mathrm{~b})$, the X-ray radiography images indicate that there are almost no porosity defect in hybrid welded joints of 5A06 alloy and Ti6Al4V alloy.

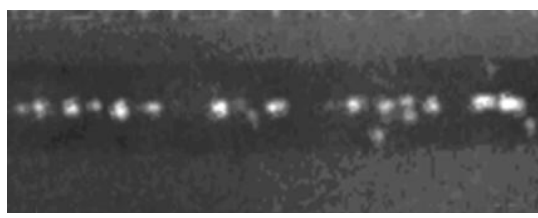

(a) Laser welding

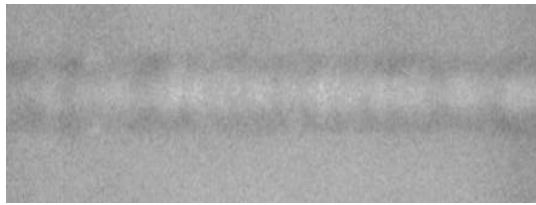

(b) Hybrid welding

Figure 7. X-ray images of 5A06 alloy welded joints.

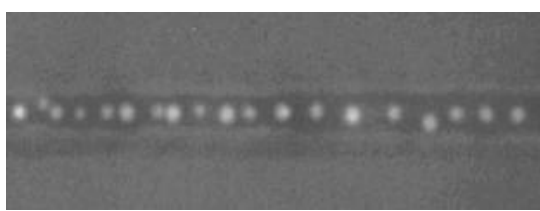

(a) Laser welding

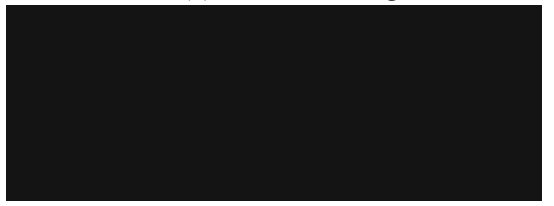

(b) Hybrid welding

Figure 8. X-ray images of Ti6Al4V alloy welded joints.

\subsection{Tensile shear test}

Tensile shear test was performed at room temperature. The tensile shear load of hybrid welded joints and laser welded joints with optimization parameters were compared and analyzed. Figure 9 shows the tensile shear load per unit length (tensile shear load/test sample width, $\mathrm{N} / D$, and $D$ is as shown in Figure 2) of 5A06 alloy welded joints. Figure 10 shows the tensile shear load per unit length of Ti6Al4V alloy welded joints. The results indicate that the tensile shear load per unit length of 5A06 alloy hybrid welded joints increase $21 \%$ compared with that of laser welded, and the tensile shear load per unit length of Ti6Al4V alloy hybrid welded joints increase $15 \%$ compared with that of laser welded.

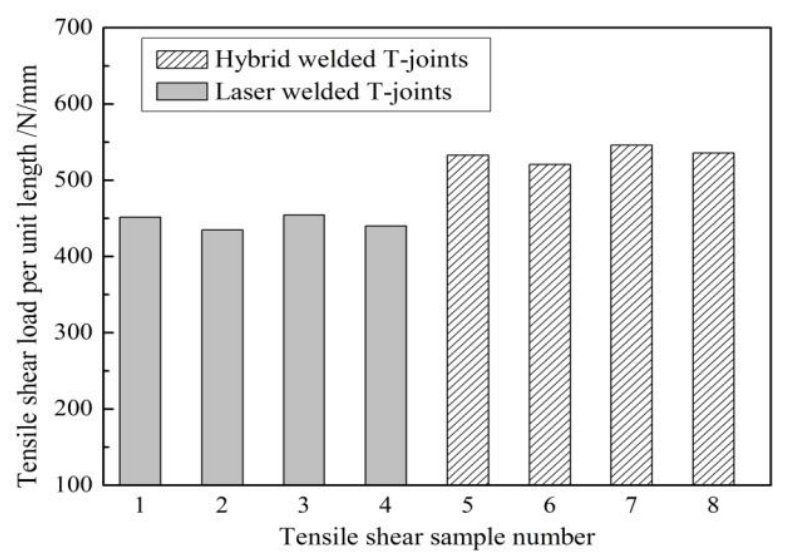

Figure 9. Tensile shear load of 5A06 alloy welded joints. 


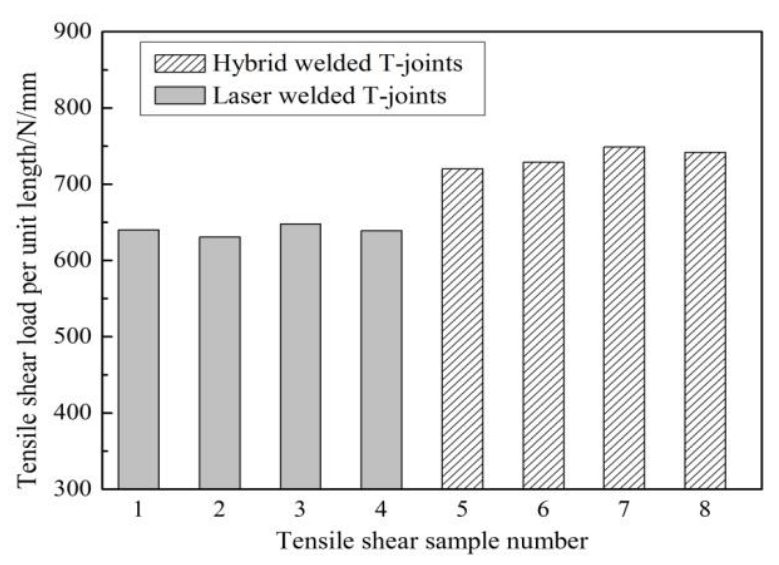

Figure 10. Tensile shear load of Ti6Al4V alloy welded joints.

\subsection{Discussions}

When the T-joints were accomplished by laser welding, although the skin and stringer were placed in jigs, there was small gap between skin and stringer, as shown in Figure 3(a) and Figure 4(a). When the T-joints were accomplished by laser-additional current hybrid welding as shown in Figure 1, the double wheel electrode could make the skin and stringer contact with each other tightly, as shown in Figure 3 and Figure 4. During laseradditional current hybrid welding, resistance heat generated when the additional current flowed through specimen which was preheated, so the laser absorption rate of metal specimen improved and then increasing the energy efficiency of the laser.

In addition, when the additional current flowed through molten pool, additional Joule heating was provided, and the magnetic field was induced because of no uniform current distribution in the molten pool and then Lorenz force was generated with the interaction between current and magnetic. The weld width at faying surface of hybrid welded joints increased compared with that of laser welding, which was mainly ascribed to preheat effect, additional Joule heating effect and Lorenz force effect. No matter laser- additional current hybrid welded aluminum alloy and titanium alloy $\mathrm{T}$-joints, the larger weld width at faying surface was acquired with higher current as shown in Figure 5 and Figure 6.

Compared with Ti6Al4V titanium alloy, the laser absorption rate of 5A06 aluminum alloy is more apt to improve with preheat effect, and additional Joule heating effect and Lorenz force effect are more outstanding because of difference on resistivity, thermal conductivity, density, special heat, viscosity and Hartmann number[8,9]. So the influence of current on 5A06 alloy weld width at faying surface is more obvious compared with Ti6Al4V alloy, shown in Figure 5 and Figure 6. When laser- additional current hybrid welded titanium alloy $\mathrm{T}$-joints, the titanium alloy oxidized more severely with resistance heating shown in Figure 4.

With the additional current flowing through molten pool, electric field effect and Lorenz force effect contribute to the stability of the keyhole and molten metal flow, which is important to greatly reduce porosity defect which exists in laser welded joints, as shown in Figure 7 and Figure 8.

Tensile shear test results show that weld width at the faying surface is the main controlling factor of welded joint shear resistance. As shown in Figure 9 and Figure 10 , the tensile shear force rises mainly with increasing weld width at the faying surface. The tensile shear strength of aluminum alloy welded joints by laseradditional current hybrid welding more significantly improve compared with titanium alloy owing to greater increase of weld width at the faying surface.

\section{Conclusions}

1. During laser-additional current hybrid welded Tjoints, the skin and stringer contact with each other tightly and the weld width at faying surface increase obviously compared with that of laser welded.

2. The weld width at faying surface is larger with higher current for aluminum alloy and titanium alloy welded T-joint, and the effect of current on aluminum alloy is more obvious compared with that of titanium alloy.

3. Porosity defect in the weld decreases relative to laser weld and nearly eliminated by laser-additional current hybrid welding process both for aluminum alloy and titanium alloy.

4. The tensile shear force rises mainly with increasing weld width at the faying surface. The tensile shear load of aluminum alloy and titanium alloy hybrid welded joints respectively increase $21 \%$ and $15 \%$ compared with themselves of laser welded.

\section{Acknowledgments}

This work was supported by $12^{\text {th }}$ five-year Science $\&$ Technology Foundation of Jilin Educational Committee and Jilin Province Postdoctoral Initial Research.

\section{References}

1. J. Romanoff, P. Varta, H. Remes, Mar. Struct. 20, 12 (2007)

2. J. Jelovica, J. Romanoff, S. Ehlers, P. Varsta, J. Const. Steel Res. 77, 10 (2012)

3. J. Romanoff, H. Remes, G. Socha, M. Jutila, P. Varsta, Thin-Wall Struct. 45, 4 (2007)

4. E.M. Knox, M.J. Cowling, I.E. Winkle, Mar. Struct. 11, 4-5 (1998)

5. Y. Zhao, L.L. Zhou, Q.Z. Wang, K. Yan, J.S. Zou, Mater. Design 57, 5 (2014)

6. D. Frank, H. Remes, J. Romanoff, Int. J. Fatigue 33, 2 (2011)

7. W.W. Duley, Laser welding, A Wiley-Interscience Publication, Canada (1999)

8. M. Kern, P. Berger, H. Hugel, Weld J. 79, 3 (2000)

9. F. Vollertsen, C. Thomy, J. Laser Appl. 18, 1 (2005) 